\title{
Drug Repurposing Approaches for the Treatment of Influenza Viral Infection: Reviving Old Drugs to Fight Against a Long-Lived Enemy
}

\begin{abstract}
Andrés Pizzorno, Blandine Padey, Olivier Terrier ${ }^{* \dagger}$ and Manuel Rosa-Calatrava ${ }^{* t}$
Virologie et Pathologie Humaine-VirPath Team, Centre International de Recherche en Infectiologie (CIRI), INSERM U1111, CNRS UMR5308, ENS Lyon, Université Claude Bernard Lyon 1, Université de Lyon, Lyon, France
\end{abstract}

Influenza viruses still constitute a real public health problem today. To cope with the emergence of new circulating strains, but also the emergence of resistant strains to classic antivirals, it is necessary to develop new antiviral approaches. This review summarizes the state-of-the-art of current antiviral options against influenza infection, with a particular focus on the recent advances of anti-influenza drug repurposing strategies and their potential therapeutic, regulatory and economic benefits. The review will illustrate the multiple ways to reposition molecules for the treatment of influenza, from adventitious discovery to in silico-based screening. These novel antiviral molecules, many of which targeting the host cell, in combination with conventional antiviral agents targeting the virus, will ideally enter the clinics and reinforce the therapeutic arsenal to combat influenza virus infections.

Keywords: influenza virus, antivirals, antiviral resistance, drug repurposing, drug repositioning, drug discovery, drug combination, transcriptional profiling

\section{INFLUENZA VIRUSES, A LONG-LIVED THREAT FOR POPULATIONS}

"A piece of bad news wrapped up in a protein," definition of a virus by Sir Peter Medawar.

Despite its apparent blandness for the collective mindset of an important portion of the society, the intrinsic morbidity and mortality as well as the related deaths because of bacterial superinfections or exacerbation of chronic illnesses, make of influenza infections a major and recurrent global public health concern. Indeed, human influenza type A and B viruses are responsible for annual flu epidemics marked by up to 1 billion infections, 3-5 million severe cases and 300,000-650,000 deaths worldwide, with an huge economic burden in terms of medical visits, hospitalizations, work/school absenteeism. and productivity loss (1-3). As members of the Orthomyxoviridae family, influenza viruses (type A, B, C, or D) are enveloped viruses harboring a negative-sense single-stranded RNA segmented genome. In such segmented nature of the viral genome resides the capacity of influenza viruses to form new reassortant strains following the concomitant infection of a host with more than one strain of human, and/or animal origin, a phenomenon so far observed only among type A influenza viruses [reviewed in (4)]. Owing to viral reassortment, the genetic baggage of progeny viruses does not exactly match that of one of the "parental" strains but a combination of both. Depending on the specific combination of genetic segments, and notably in the case of a human influenza strain acquiring the Hemagglutinin (HA) and/or Neuraminidase 
(NA) major surface antigens from animal origin, reassortment events can result in an antigenic shift, defined as the generation of a new virus with antigenic properties drastically different from those of the circulating strains. Should this new variant be sufficiently antigenically different to escape the repertoire of pre-existing immunity in the population, it might rapidly disseminate and replace the circulating strains, hence triggering a global influenza pandemic. Although relatively rare-three veritable pandemics occurred during the 20th Century and one so far in the twenty-first century-the outbreak of pandemics is a quite unpredictable event that might entail potentially devastating effects [reviewed in (5)], particularly considering the contemporary state of affairs regarding global transportation and trade, migration, and the narrowing interface between rural and overcrowded urban areas.

Influenza vaccination constitutes the most effective strategy to prevent seasonal flu and its clinical complications, mainly among high-risk populations such as very young children, the elderly, pregnant women, immunocompromised patients as well as people with obesity, diabetes, or cardiorespiratory comorbidities $(6,7)$. Nevertheless, current flu vaccination still presents several limitations that make it fall short of expectations in terms of effectiveness. The short duration of vaccine-induced immunity coupled with the intrinsic antigenic drift of influenza viruses resulting from the gradual accumulation of point mutations in the antigenic sites of the HA (and to a lesser extent the NA) surface protein underscore the need of the annual reformulation of vaccine composition. Moreover, the length of the current vaccine manufacturing process (at least 6 months to produce sufficiently large vaccine quantities) demands continual strain selection to be done approximately 8 months before the next flu season $(6,8)$. Should an antigenic drift occur during this time window, the possibility of a mismatch between the vaccine composition and circulating strains might negatively affect protection. Even in the absence of seasonal mismatches or the emergence of pandemic strains, insufficient vaccine coverage and suboptimal uptake in specific target groups (i.e., the elderly or the immunocompromised) also compromise vaccine effectiveness. Furthermore, despite the recent progress made in the pursue of the "Holy Grail" of a universal influenza vaccine that can provide broader, long-lasting protection against both matching, and antigenically diverse influenza strains $(9,10)$, their clinical effectiveness remains to be evaluated, hence highlighting the need of complementary therapeutic approaches to manage influenza infections.

Besides vaccination, antiviral drugs represent the other pillar for the control of seasonal influenza epidemics and play a central role as major prophylactic and therapeutic agents in the event of a pandemic outbreak. In that regard, this review summarizes the state-of-the-art of current antiviral options against influenza infection, with a particular focus on the recent advances of anti-influenza drug repurposing strategies and their potential therapeutic, regulatory and economic benefits. This review presents examples of the multiple ways to reposition molecules for the treatment of influenza, from adventitious discovery to in silico-based screening. These novel antiviral candidates, many of which target the host cell, could also be used in combination with conventional virus-targeted antiviral agents in order to reinforce our very limited therapeutic arsenal against influenza virus infections.

\section{CURRENT ANTIVIRAL OPTIONS FOR TREATING INFLUENZA INFECTIONS}

As mentioned above, antivirals are key players in pandemic preparedness programs, being the first choice for the treatment of infected patients as well as for preventive post-exposure prophylaxis of those potentially exposed to the new virus, especially during the initial pandemic period in which no vaccine is available. Antivirals are as well important in the normal seasonal setting. Although their use is mostly focused on the treatment of severely ill patients and the immunocompromised, some countries, including the USA and Japan, regularly resort to antivirals for the management of uncomplicated influenza in otherwise healthy patients $(11,12)$. To date, only two classes of antiviral agents are globally approved and available for the treatment of influenza infections: M2 ion-channel blockers and neuraminidase (NA) inhibitors. The first class includes adamantane derivatives, amantadine and rimantadine, which inhibit proton conductivity of the M2 ion channel of influenza A viruses hence preventing the viral uncoating step of the viral replication cycle. Nevertheless, although quite efficient in their early days, widespread dissemination of the S31N (and to a much lesser extent V27A) M2 resistance mutation in post-2006 H3N2 and post-2009 $\mathrm{H} 1 \mathrm{~N} 1$ circulating strains prompted the $\mathrm{WHO}$ to remove both amantadine and rimantadine from the list of recommended anti-influenza agents for clinical use, in 2009 (6). As a result, NA inhibitors stand as the only influenza antivirals currently recommended by the WHO (13).

NA inhibitors are competitive analogs of sialic acid, the preferred influenza receptor on the host cell's surface. By binding to the broadly conserved active site of the NA, NA inhibitors interfere with the sialidase enzymatic activity of the viral protein, which is essential for the release of newly formed progeny viruses from the infected cell, hence preventing the spread of infection to the rest of the respiratory tissue (14). Three NA inhibitors are currently licensed worldwide for the treatment of influenza A and B infections: oseltamivir, zanamivir, and peramivir. Oral oseltamivir (administered as its prodrug oseltamivir phosphate) is the most largely used of the three, whereas inhaled zanamivir is not recommended for very young children nor for individuals with underlying respiratory conditions, and intravenous peramivir is prioritized in hospitalized patients that cannot receive oral treatment (15). Additionally, inhaled laninamivir, a single-dose long lasting NA inhibitor, is approved in Japan for the prevention and treatment of influenza A and B in both adult and pediatric patients (16). It is important to note that some degree of skepticism is still present regarding the real efficacy of NA inhibitors, notably following the 2014's Cochrane clinical meta-analysis that reported only a minimal shortening of influenza symptoms in children and adults with uncomplicated influenza but not in hospitalized patients (17). Nevertheless, actual evidence-based consensus points to 
a moderate efficacy of NA inhibitor treatment in reducing symptom duration, pneumonia, hospitalization and mortality, especially when administered within $48 \mathrm{~h}$ from symptom onset $(18,19)$. Conversely, delayed treatment initiation is associated with compromised efficacy but may yet be beneficial in atrisk patients. Moreover, the emergence of NA inhibitor-resistant virus variants is a matter of concern, with particularly higher frequencies among children and the immunocompromised (20). The H275Y NA substitution is the main mutation responsible for both oseltamivir and peramivir resistance in $\mathrm{H} 1 \mathrm{~N} 1$ viruses while $\mathrm{R} 292 \mathrm{~K}$ and E119V are the most commonly reported in H3N2 viruses, these latter two also conferring reduced susceptibility to zanamivir and laninamivir $(17,21)$. Even if nowadays the prevalence of drug-resistance in circulating strains is quite low $(\leq 1 \%)$, evidence form pre-2009 seasonal strains has proved that, given the appropriate conditions, resistance could rapidly disseminate to attain a prevalence of $90-100 \%(17,21)$. In that regard, the relatively recent detection of localized clusters of NA inhibitor-resistant H1N1pdm09 viruses harboring the H274Y mutation combined or not with I222R/V NA substitutions (22, 23) strengthens the importance of continuous surveillance.

In addition to M2 ion channel blockers and NA inhibitors, two small molecules that target the viral RNA-dependent RNA polymerase, favipiravir and baloxavir marboxil, are undergoing clinical evaluation in the US and Europe but already obtained approval by Japanese Health authorities. Favipiravir is a nucleoside analog that acts as a competitive inhibitor of viral polymerase substrate, approved since 2014 for the treatment of influenza infections with newly emerging strains and/or resistant to other antiviral agents. However, despite the apparent high threshold for drug resistance (24) and broad-spectrum antiviral potential notably validated in the context of recent Ebola virus outbreaks (25), recent results of Phase II/III randomized trials on its therapeutic efficacy against uncomplicated influenza were not completely conclusive (26). Baloxavir marboxil is a selective inhibitor of the cap-dependent endonuclease activity of the influenza viral PA polymerase subunit (27), therefore interfering with the cap-snatching activity of the viral polymerase complex. In that regard, a very recent report disclosed for the first time the results of two randomized (Phases II and III) clinical trials evaluating the efficacy of a single-dose oral treatment with baloxavir marboxil in otherwise healthy outpatients with acute uncomplicated influenza, compared with placebo and a regular 5-day treatment with oseltamivir (28). Overall, baloxavir marboxil and oseltamivir moderately reduced the time to symptom alleviation compared to placebo, while the former outperformed the two others in reducing viral loads. These results prompted the US Food and Drug Administration (FDA) to approve Xofluza ${ }^{\circledR}$ (baloxavir marboxil) for the treatment of acute uncomplicated influenza in patients 12 years of age and older who have been symptomatic for no more than $48 \mathrm{~h}$ (29). Nevertheless, this first antiviral flu treatment with a novel mechanism of action approved by the FDA in nearly 20 years does not seem to escape the problem of all other virus-targeted anti-influenza agents. The emergence of virus variants (mostly due to the I38T/M PA amino acid substitutions) conferring significant levels of reduced susceptibility to baloxavir marboxil was observed in up to $9.7 \%$ of the patients receiving the drug $(28,30)$.

Overall, Table 1 summarizes the main characteristics of the abovementioned currently available antiviral options for influenza. Such limited therapeutic arsenal coupled with the recurrent risk of emerging drug-resistance highlights the obvious unmet need of novel approaches to complement existing therapies with new anti-influenza drugs.

\section{WHAT IS DRUG REPURPOSING?}

\begin{abstract}
"The most fruitful basis for the discovery of a new drug is to start with an old drug," famously stated the 1998 Nobel Prize in Physiology and Medicine Laureate, Sir James Black.
\end{abstract}

Despite the enormous scientific and technological advances that the field of biomedical research has witnessed in the last 20-30 years, this scenario failed to efficiently translate into significant improvement on the success rate of the classic "from the bench to the bedside" target-centered, mechanistically biased de novo drug discovery process (38). Indeed, with an almost unchanged total number of 25-30 novel molecules out of the approximately 50 new drugs yearly approved by the FDA (39), biopharmaceutical experts estimate that only $12 \%$ of drug candidates that make it into Phase I clinical trials receive the final green light (40). In other words, of 5,000-10,000 compounds that come from classic drug discovery, only one is likely to be approved. The causes of this phenomenon are multifactorial, including the targeting of more intricate diseases, limitations of reductionist experimental models to reproduce biological complexity, increased regulatory stringency, tolerability issues, and unexpected side effects. Altogether, the total R\&D process leading to the introduction of a new drug in the market demands on average 13-15 years and between U\$S 1.5 and 2.6 billion (40-42).

In this context, drug repurposing stands as a worthwhile attractive alternative to fill part of this so-called innovation gap. Drug repurposing, also termed drug repositioning, defines the process of identifying and validating a new therapeutic indication for an existing or developmental drug $(38,42,43)$. The basis of drug repurposing relies on bypassing long, risky and expensive preclinical and early clinical evaluation stages by focusing on available extensive human clinical, pharmacokinetics and safety data as the starting point for further development (Figure 1). An extended definition could also include not only already marketed drugs but also "sleeping" candidates that have seen their development abandoned in advanced phases of clinical evaluation (e.g., Phase II/III trials) due to non-satisfactory efficacy for their first intended medical use, which might find a second life in a novel therapeutic indication Noteworthy, repurposing arguably accounts for $30 \%$ of the new drug products approved by the FDA (44).

In practice, the concept of drug repurposing represents a broad term encompassing many different, though not mutually exclusive, experimental approaches to recognize potential new applications outside the scope of the original medical indication (42), including: 
TABLE 1 | Currently approved drugs for the treatment of influenza viral infections.

\begin{tabular}{|c|c|c|c|c|c|c|}
\hline $\begin{array}{l}\text { International } \\
\text { non-proprietary } \\
\text { name }\end{array}$ & $\begin{array}{l}\text { Pharmaceutical } \\
\text { brand names } \\
\text { (examples) }\end{array}$ & Antiviral class & Antiviral activity & Clinical indication & $\begin{array}{l}\text { Resistance } \\
\text { reported }\end{array}$ & $\begin{array}{l}\text { Discovery/ } \\
\text { Reference }\end{array}$ \\
\hline $\begin{array}{l}\text { Amantadine } \\
\text { hydrochloride }\end{array}$ & $\begin{array}{l}\text { Mantadix } \\
\text { Symmetrel } \\
\text { Symadine } \\
\text { Osmolex ER }\end{array}$ & $\begin{array}{l}\text { M2 ion-channel } \\
\text { blockers }\end{array}$ & $\begin{array}{l}\text { Blocks influenza virus uncoating } \\
\text { and entry into host cell }\end{array}$ & $\begin{array}{l}\text { High risk old adults and children } \\
\text { Prophylaxis } \\
\text { Or treatment } 24 / 48 \text { post } \\
\text { symptoms appearance }\end{array}$ & YES & $\begin{array}{c}1963 \\
(31)\end{array}$ \\
\hline $\begin{array}{l}\text { Rimantadine } \\
\text { hydrochloride }\end{array}$ & $\begin{array}{l}\text { Roflual } \\
\text { Flumandine }\end{array}$ & & & & & $\begin{array}{c}1969 \\
(32)\end{array}$ \\
\hline Oseltamivir phosphate & Tamiflu & NA inhibitors & $\begin{array}{l}\text { Sialic acid structural analog, } \\
\text { competitive inhibitor of the } \\
\text { influenza viral neuraminidase } \\
\text { substrate }\end{array}$ & $\begin{array}{l}\text { Children, adolescent and adults } \\
48 \mathrm{~h} \text { from symptom onset }\end{array}$ & YES & $\begin{array}{c}1998 \\
(33)\end{array}$ \\
\hline Zanamivir & Relenza & & & $\begin{array}{l}\text { Children and adults } \\
\geq 5 \text { years (prophylaxis) } \\
\geq 7 \text { years (treatment) } \\
48 \mathrm{~h} \text { from symptom onset }\end{array}$ & & $\begin{array}{c}1993 \\
(34)\end{array}$ \\
\hline Peramivir & $\begin{array}{l}\text { Rapivab } \\
\text { Peramiflu } \\
\text { Rapiacta }\end{array}$ & & & $\begin{array}{l}\text { Children, adolescent and adults } \\
\text { intravenous peramivir is prioritized in } \\
\text { hospitalized patients that cannot } \\
\text { receive oral treatment } \\
48 \mathrm{~h} \text { from symptom onset }\end{array}$ & & $\begin{array}{c}2000 \\
(35)\end{array}$ \\
\hline Laninamivir octanoate & Inavir & & & $\begin{array}{l}\text { Children and adults } \\
\text { inhaled laninamivir } \\
\text { Prevention adults and } \\
\text { pediatric patients }\end{array}$ & & $\begin{array}{c}2000 \\
(36)\end{array}$ \\
\hline Favipiravir & Avigan & $\begin{array}{l}\text { Polymerase } \\
\text { inhibitor }\end{array}$ & $\begin{array}{l}\text { Nucleoside analog, competitive } \\
\text { inhibitor of viral RNA-dependent } \\
\text { RNA polymerase substrate }\end{array}$ & $\begin{array}{l}\text { Limited to cases in which } \\
\text { other influenza antiviral drugs are } \\
\text { ineffective or not sufficiently effective }\end{array}$ & YES & $\begin{array}{c}2002 \\
(37)\end{array}$ \\
\hline Baloxavir marboxil & Xofluza & & $\begin{array}{l}\text { Selective inhibitor of the } \\
\text { cap-dependent endonuclease } \\
\text { activity of the influenza viral PA } \\
\text { polymerase subunit }\end{array}$ & $\begin{array}{l}\text { Treatment of acute uncomplicated } \\
\text { influenza in patients } 12 \text { years of age } \\
\text { and older who have been } \\
\text { symptomatic for no more than } 48 \mathrm{~h}\end{array}$ & & $\begin{array}{c}2018 \\
(27)\end{array}$ \\
\hline
\end{tabular}

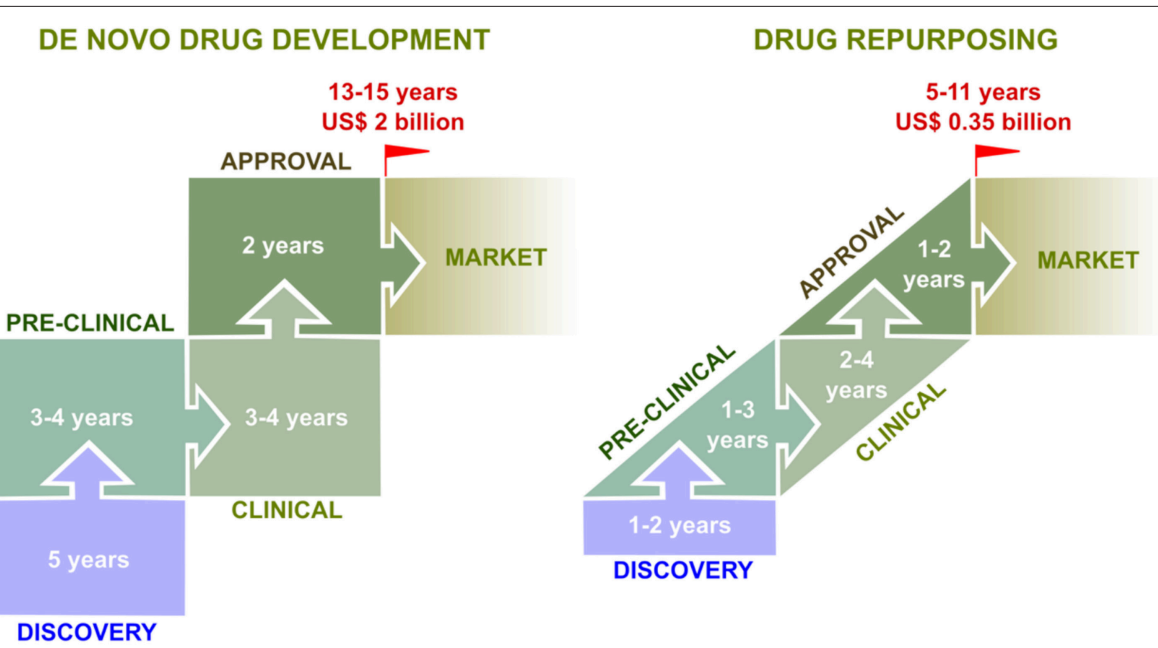

FIGURE 1 | From the bench to the bedside: comparison between de novo drug development and drug repurposing. De novo (classic) drug development constitutes a time-consuming and expensive process. From initial discovery to market, it generally takes $13-15$ years and costs up to US\$ 2 billion, with a very low success rate (10\%). In contrast, drug repurposing approaches offer several advantages. Indeed, the time frame from discovery to market is shorter (5-11 years), less expensive (US\$ 350 million), and with a higher success rate (30\%), mostly because a large part of preclinical and clinical testings (e.g., safety, formulation, posology) have been already performed for the drug's initial therapeutic indication $(41,42)$. 


\section{Serendipitous Observations}

Some of the best-known success stories of drug repurposing have their starting point on serendipitous observations recorded in the context of either preclinical models of disease or pre/post-approval clinical trials, leading to a subsequent rationalized evaluation and validation of the new treatment potential (41). Thalidomide and sildenafil are two examples of such key observations. The first one was initially introduced as an antinausea for pregnant women but had to be rapidly removed from the market due to its teratogenicity. Further research enabled this molecule as well as some derivatives to be repurposed for the treatment of leprosy and multiple myeloma (45). Sildenafil, on the other hand, never reached the market for its originally intended use in the treatment of hypertension but the observed side-effects on erectile dysfunction ended in its approval in under the commercial name of Viagra ${ }^{\circledR}$. More recently, sildenafil found a third life under the commercial brand of Revatio ${ }^{\circledR}$ for the treatment of pulmonary hypertension (46).

\section{Target-Based Repurposing}

Although serendipitous observation has historically proved its usefulness, the intrinsic necessity of the casual observation of an unintended and usually infrequent second benefit poses a significant hurdle for exploiting the full potential of drug repurposing, for which more controlled, systematic methodologies are needed. Target-based repurposing relies on having previous knowledge of the specific molecular or cellular determinant/function target recognized by the drug intended to be repurposed. If new research finds out that target is plays an important role in a condition or disease other than the original indication, there is a potential for repurposing. Of note, the target might but not necessarily has to play the same role in both conditions. For example, in the case of the previously mentioned favipiravir, the drug plays the same role as viral RNA polymerase inhibitor against both influenza and Ebola viruses. On the other hand, the Abelson tyrosine-protein kinase 2 (Abl2), target of the anticancer drug imatinib, has been found to be required for efficient fusion and release of severe acute respiratory syndrome coronavirus (SARS-CoV) and Middle East respiratory syndrome coronavirus (MERS-CoV) pseudovirions into the cytoplasm of the infected cell, a key step for viral replication (47).

An alternative scenario of target-based repurposing can happen when a particular drug of known mechanism of action is found to have a new molecular/cellular target, and this previously unrecognized second target is associated with a different disease. The molecule is therefore said to present polypharmacologyrelated features, meaning the capacity to act on multiple targets $(48,49)$. Polypharmacological phenomena includes both a single drug acting on multiple targets of a unique disease pathway, or a single drug acting on multiple targets pertaining to multiple disease pathways (50). In fact, polypharmacology is usually responsible for treatment toxicity or other undesirable adverse events, but some of these "side-effects" might also lead to drug repurposing, as further exemplified in the next sections. During the last decade, an increasing number of studies converged on proposing that many drugs, initially designed for a unique therapeutics target, are in fact expected to hit on average between 6 and 13 different targets $(51,52)$.

\section{Phenotypic Screening}

One major limitation of the target-based drug repurposing model relies on its dependence on the existing scientific knowledge of the drug/disease mechanism(s) of action/pathology as well as on potential alternative targets, which is usually incomplete. In other words, we cannot fully anticipate the repurposing potential of a drug unless we have characterized its molecular/cellular target(s), or if we do not know that a given drug target plays an important role on a particular disease. Phenotypic screening of bioactive molecule libraries in different experimental cellbased or in vivo disease models without the need of a priori knowledge or consideration of the target and/or mechanism of action the candidate was designed to modulate can provide valuable contribution to overcome this constraint (53). Indeed, despite this approach has been questioned due to the fact that the expected altered phenotype readout as a surrogate of an exploitable biological effect induced by the drug candidate might account for an important number of false positive "hits," it is nonetheless true that the contribution of highthroughput phenotypic screening to first-in-class small molecule drug discovery exceeded that of target-based approaches (54, $55)$. In that regard, many well-annotated collections of smallmolecule libraries could be readily made available through different collaborative and/or commercial partnerships in order to accelerate drug repurposing through hypothesis biased or unbiased phenotypic screening [reviewed in (54-57)].

\section{In silico-Assisted Repurposing}

With the advent of big data and systems biology, computer-based approaches are gaining increasing acceptance in the field of drug discovery, and drug repurposing is not an exception. Besides the inclusion of constantly emerging "omics" (e.g., transcriptomic, proteomic, metabolomic) data to expand our current knowledge of drug/disease-associated mechanisms, in silico data mining and modeling tools have pushed our capacity to analyze data to the next level (58-60). These in silico methods include the screening of chemical, biological, and text databases, analysis of quantitative structure-activity relationships, pharmacophores, homology models, and other molecular modeling approaches as well as network analysis of biological functions, machine learning and almost any other analysis tools that include using a computer (61-64). In that regard, proper mining of biological, chemical and clinical datasets, has proved effective in unveiling novel relationships $(65,66)$. Moreover, another level of complexity can be added by combining, for example, epidemiologic information obtained in-house and/or from publicly available literature databases with in vitro experimental molecule screenings with the aim to identify novel indications, as in the case of digoxin and prostate cancer $(67,68)$. Indeed, the real power of computer-assisted drug repurposing resides on adopting an integrative strategy that combines the predictive and analytic capacity of in silico tools with some of the target biased or unbiased experimental evaluation/validation methods previously mentioned. This "systems pharmacology" approach 
(69-71) across the boundaries of traditional disciplines would put researchers in a better-informed position to design more comprehensive repurposing strategies with more effective predictive capacity and, hopefully, improved candidate success rates.

\section{THE EMERGENCE OF DRUG REPURPOSING APPROACHES IN THE FIELD OF ANTIVIRAL DRUG DISCOVERY}

These last 10 years, there has been a remarkable growing interest for drug repurposing in the field of antiviral drug discovery, fueled by the incontestable reality of many known viral infections still lacking specific treatment. This interest is inversely correlated with the very low number of classic antiviral molecules that have been market-approved these last 5 years, mostly for the treatment of hepatitis C virus or HIV-related pathologies (72). The best example of antiviral drug repurposing approaches are emerging viruses such as Ebola, Zika virus or MERS-CoV, for which there is an urgent and cost-effective need for therapeutics solutions. Indeed, to rapidly propose a solution in the context of a viral outbreak, one interesting approach consists to look at the available pharmacopeia used to treat pathogens. For example, chloroquine, a major antimalarial drug, has been proposed for the treatment of filoviral infections, and more largely for the treatment of other emerging pathogens, as it targets endosomal acidification, a pivotal step in the replication cycle of a large number of viruses $(73,74)$. Another interesting illustration is the previously cited example of favipiravir, which proved its repurposing potential for the treatment of Zika or Ebola viral infections $(25,43,75)$.

\section{DRUG REPURPOSING FOR INFLUENZA VIRAL INFECTION}

As mentioned before, the intrinsic ever-evolving nature of the virus, high transmissibility, host promiscuity, suboptimal vaccine efficacy, limited antiviral arsenal, and zoonotic, and pandemic potential are more than convincing factors to consider influenza viruses as attractive targets for drug repurposing. Despite many interesting omics-based approaches (76) or high-throughput screening of specific drug libraries, such as kinase inhibitors (77), no anti-influenza agent issued from drug repurposing has yet reached regulatory market approval. However, advances made during the last years forecast optimism. The following selected examples constitute a very good illustration of the diversity and capabilities of drug repurposing strategies for influenza infection. An exhaustive list of anti-influenza candidates issued from drug repurposing approaches is presented in Table 2.

The case of statins is arguably the best-known example of antiinfluenza repurposing issued from clinical observations. In the early 2000s, clinicians observed that besides the cardioprotective activity of statins, these hydroxyl methylglutaryl-coenzyme A (HMG-CoA) reductase inhibitors approved for their use as cholesterol metabolism regulators could have pleiotropic antiinflammatory and immunomodulatory effects, which could be of benefit to improve survival of patients with severe influenza (7880 ). Although many mouse and observational studies account for the protective role of statins in pneumonia, most in vivo studies reported so far failed to clearly demonstrate such a beneficial effect in the specific context of influenza infection (99-102). On the other hand, a few but not all observational studies highlighted an association between statin treatment with up to $41 \%$ reduction of 30 -day all-cause mortality in patients hospitalized with laboratory-confirmed seasonal influenza (103105). A randomized placebo-controlled Phase II clinical trial (NCT02056340) aimed at evaluating the potential effect of atorvastatin to reduce the severity of illness in influenza-infected patients is currently undergoing.

Nitazoxanide is another illustration of a serendipitous repurposing approach, and probably one of the most promising examples. Nitazoxanide is a thiazolide anti-infective initially licensed for the treatment of parasitic infections, for which antiinfluenza properties were first documented by Rossignol et al. (81). Interestingly, the proposed mode of action of nitazoxanide toward influenza is clearly distinct to that for which it was designed in its initial indication, acting at the post-translational level by selectively blocking the maturation of the viral glycoprotein HA, with a consecutive impact on its intracellular trafficking and insertion into the host plasma membrane (81, 106). This drug presents potent antiviral activity against a large panel of circulating strains (82). The effectiveness of nitazoxanide in treating patients with non-complicated influenza was successful in a Phase IIb/III trial (107) and is currently being assessed in a Phase III clinical trial (NCT01610245).

BAY81-8781/LASAG (D, L-Lysine acetylsalicylate-glycine), a modified version of the anti-inflammatory drug acetylsalicylic acid (ASA) licensed for intravenous and inhalation delivery, is currently investigated as an anti-influenza treatment as a result of a mixed serendipitous and target-based repurposing strategy. It was initially shown that ASA had interesting antiviral effects against influenza viruses in vitro and in vivo via the inhibition of the NF-kB activating kinase IkkB, which negatively impacts influenza vRNP transport and release of infectious viral particles (108-110). However, due to the pharmacokinetic limitations of ASA, the LASAG modified version with improved stability and tolerability was developed. Like ASA, this molecule also demonstrates antiviral activity against several human and avian influenza viruses in vitro. In a mouse infection model, inhalation of LASAG resulted in reduced lung viral titers and protection of mice from lethal infection (85). More recently, a Phase II proof-of-concept study comparing LASAG versus placebo in patients with severe influenza (all patients receiving Tamiflu as standard of care treatment) demonstrated that aerosolized LASAG improved the time to symptom alleviation compared to placebo, despite the absence of a statistically significant reduction of viral load in LASAG-treated group (86).

Naproxen constitutes a nice example of in-silico \& targetbased strategy for the identification of new antivirals. Lejal et al. used a structure-based modeling approach to identify drugs of interest directed against the nucleoprotein (NP) of influenza A virus, using the X-ray structure of the RNA-free NP of $\mathrm{H} 1 \mathrm{N1}$ as prototype. An in-silico screening, focused of a defined specific 


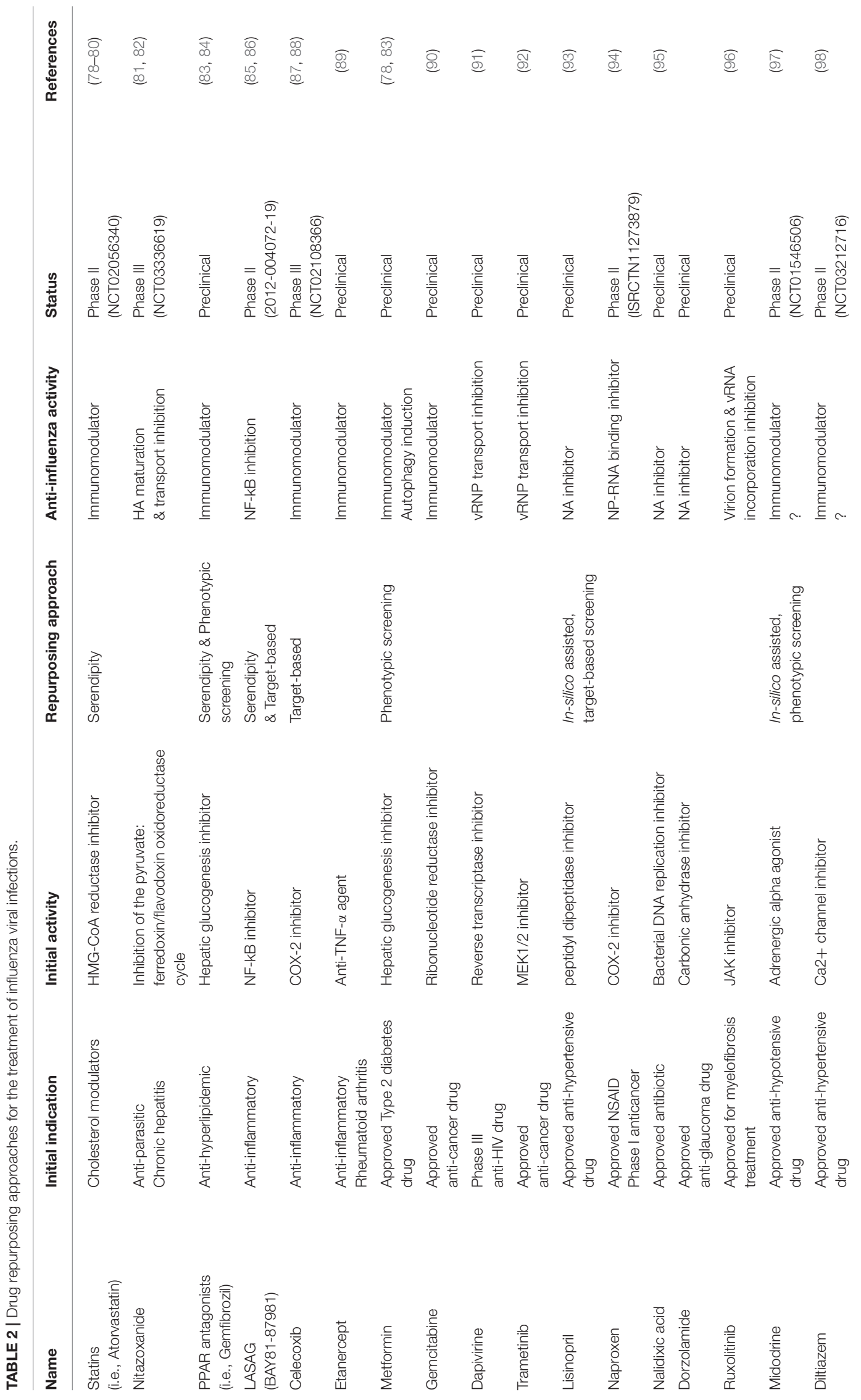


site of NP structure, has identified naproxen, a known inhibitor of inducible cyclooxygenase type 2 (COX-2) commonly used as non-steroidal anti-inflammatory drug. This identified molecule has shown antiviral properties against influenza $A$ virus in vitro and in vivo (94). More recently, naproxen analogs with improved efficacy have been developed, showing high level of inhibition of both NP-RNA and NP-polymerase subunit PA complexes, without parallel inhibition of COX-2 $(111,112)$. Interestingly, in contrast to other examples of drug repurposing strategies, the example of naproxen remains virus-targeted and future works will determine if this drug will present the same Achille's heel than classic antivirals regarding selection of antiviral resistance.

The last two examples of this chapter are midodrine and diltiazem, that we identified as influenza antivirals in the context of an in-silico assisted strategy based on transcriptional profiling. An emerging approach in drug repurposing is based on signature matching, which consists of comparing a specific characteristic of a drug-its cellular signature-to that of a disease (42). This approach, mostly based on transcriptomic data, was successfully exploited to identify drug repurposing opportunities in a large range of therapeutics areas, and notably in the field of oncology and rare diseases (42). Our group was the first to transpose this approach to the field of viral infectious diseases, thanks to the development and democratization of DNA-microarray and more recently RNAseq techniques. In a proof-of-concept study using an in vitro model of infection, we postulated that host global gene expression profiling can be considered as a "fingerprint" or signature of any specific cell state, including during infection or drug treatment, and hypothesized that the screening of databases for compounds that counteract virogenomic signatures could enable rapid identification of effective antivirals (97). Among the molecules identified in silico, midodrine, an adrenergic alpha receptor agonist widely used to treat hypotension, demonstrated very interesting in vitro antiviral activities (97). These results prompted the Phase II clinical evaluation of midodrine (NCT01546506) for the treatment of uncomplicated seasonal flu in primary care centers.

Based on this previous proof-of-concept obtained from in vitro gene expression profiles, we further improved the strategy by analyzing upper respiratory tract clinical samples collected from a cohort of influenza $\mathrm{A}(\mathrm{H} 1 \mathrm{~N} 1) \mathrm{pdm} 09$-infected patients and determined their respective transcriptomic signatures. We then performed an in-silico drug screening and identified a list of candidate bioactive molecules with signatures anticorrelated with those of the patient's acute infection state. The potential antiviral properties of selected market-approved molecules were firstly validated in vitro, and the most effective compounds were further compared to oseltamivir for the treatment of influenza $\mathrm{A}(\mathrm{H} 1 \mathrm{~N} 1) \mathrm{pdm} 09$ virus infections in mice and in a physiological in vitro model of reconstituted human airway epithelia (MucilAir ${ }^{\mathrm{TM}}$ ). These results notably highlighted diltiazem, a calcium channel blocker used as an anti-hypertensive drug, as a very promising repurposed host-targeted inhibitor of influenza infection (98). An ongoing French multicenter randomized clinical trial is investigating the effect of diltiazemoseltamivir bitherapy compared with standard oseltamivir monotherapy for the treatment of severe influenza infections in intensive care units (FLUNEXT trial NCT03212716).

\section{VIRUS-TARGETED vS. HOST-TARGETED THERAPY, WHY NOT BOTH?}

\author{
"Two are better than one, because they have a good return for their \\ labor" Ecclesiastes 4:9-10.
}

The concept of antiviral combination therapy was originally pioneered for antiretroviral treatments, with the primary goal of preventing or at least delaying the emergence of drug resistance via the targeting of multiple steps of the viral cycle (113). Another expected complementary goal is to obtain additive or synergistic effects by combining drugs, a "double-trigger" effect, to increase effectiveness and/or reduce dosage. In the context of influenza infections, the combination of classic antivirals, mostly NA inhibitors, was explored by several research groups, including ours, with relatively mixed conclusions. For example, in a mouse model, the combination of oseltamivir with zanamivir was shown to be not superior to zanamivir monotherapy in the context of influenza $\mathrm{A}(\mathrm{H} 3 \mathrm{~N} 2)$ or $\mathrm{A}(\mathrm{H} 1 \mathrm{~N} 1)$ pdm09 infection (114). A clinical trial was conducted during the $\mathrm{A}(\mathrm{H} 1 \mathrm{~N} 1) \mathrm{pdm} 09$ pandemic in 2009-2010 (COMBINA trial NCT00830323) and failed to demonstrate whether oseltamivir/zanamivir combination therapy improved or reduced the effectiveness of oseltamivir alone in the treatment of influenza infections in community patients (115). Other clinical investigations have shown a greater effectiveness of such combination therapy to reduce influenza transmissibility (116).

As most alternative antiviral strategies for the treatment of influenza infections, including those related to drug repurposing and targeting the host instead of viral determinants, an emerging trend consists to propose innovative therapies that combine classic antivirals with host-targeting drugs, which starts to show promising results (87). For example, Belardo et al. have demonstrated, in cell culture-based assays using different human and avian models, that the combination of NA inhibitors and nitazoxanide presents synergistic anti-influenza effects (117). Convincing results were also obtained using a combination treatment including naproxen. In a clinical trial enrolling hospitalized patients infected by influenza $\mathrm{A}(\mathrm{H} 3 \mathrm{~N} 2)$, combination therapy with naproxen, oseltamivir, and clarithromycin showed improved efficacy in terms of hospital stay duration and patient mortality, when compared to oseltamivir treatment alone (118). In the context of the evaluation of the antiviral activity of diltiazem in the reconstituted human airway epithelium model MucilAir ${ }^{\mathrm{TM}}$, our group demonstrated that the diltiazem-oseltamivir combination treatment conferred a greater reduction of apical viral titers than that was measured with the same-dose monotherapy, with a marked delay of viral production (98). An ongoing French multicenter randomized clinical trial is investigating the effect of diltiazem-oseltamivir bitherapy compared with standard oseltamivir monotherapy for the treatment of 
severe influenza infections in intensive care units (FLUNEXT trial NCT03212716).

Altogether, these results plead in favor of the use of drug repurposing for the improvement of the current standard of care anti-influenza therapy. In contrast to other technological domains, the innovation is not necessary chasing and replacing the established standard, and future works are still necessary to investigate the real impact of these novel "host \& virus-targeted" multi-therapy approaches on the management and control of the emergence of viral resistance.

\section{CONCLUDING REMARKS}

"We do not need to find new drugs; rather we need to find the patients who can benefit from existing drugs" the saying goes. Although somehow exaggerated, this statement summarizes pretty clearly the essence behind the drug repurposing initiative. Finding new indications for already-existing drugs has many benefits, mainly by improving cost-effectiveness, reducing risks, and shortening time to market $(37,41)$. The purpose of this review was to foster discussion on drug repurposing as an option to complete and implement our current anti-influenza therapeutic arsenal. We are facing an important need for the development of novel antiviral strategies that improve treatment effectiveness-especially in the case of severe diseasesand that are less prone to selection for antiviral resistance. In that regard, the identification and validation by different and complementary means of repurposed drugs is incontestably of great interest, notably in combination with current classic virustargeted inhibitors. In addition, the deposition of data, including

\section{REFERENCES}

1. Influenza (Seasonal). World Health Organization. Available online at: http:// www.who.int/news-room/fact-sheets/detail/influenza-(seasonal) (Accessed October 28, 2018)

2. Iuliano $\mathrm{AD}$, Roguski KM, Chang HH, Muscatello DJ, Palekar R, Tempia S, et al. Estimates of global seasonal influenza-associated respiratory mortality: a modelling study. Lancet. (2018) 391:1285-300. doi: 10.1016/S0140-6736(17) 33293-2

3. Pelletier AJ, Mansbach JM, Camargo CA. Direct medical costs of bronchiolitis hospitalizations in the United States. Pediatrics. (2006) 118:2418-23. doi: 10.1542/peds.2006-1193

4. Medina RA, García-Sastre A. Influenza A viruses: new research developments. Nat Rev Microbiol. (2011) 9:590-603. doi: $10.1038 /$ nrmicro2613

5. Krammer F, Smith GJD, Fouchier RAM, Peiris M, Kedzierska K, Doherty PC, et al. Influenza. Nat Rev Dis Primers. (2018) 4:3. doi: 10.1038/s41572-018-0002-y

6. Paules C, Subbarao K. Influenza. Lancet. (2017) 390:697-708. doi: 10.1016/S0140-6736(17)30129-0

7. Restivo V, Costantino C, Bono S, Maniglia M, Marchese V, Ventura G, et al. Influenza vaccine effectiveness among high-risk groups: a systematic literature review and meta-analysis of case-control and cohort studies. Hum Vaccin Immunother. (2017) 14:724-35. doi: 10.1080/21645515.2017.1321722

8. Buckland BC. The development and manufacture of influenza vaccines. Hum Vaccin Immunother. (2015) 11:1357-60. doi: $10.1080 / 21645515.2015 .1026497$ negative results, into public database should be encouraged, as it would facilitate efforts to repurpose licensed or orphaned drugs, and consecutively increase our chances to find new efficient antiviral drugs. With a growing number of academic groups and pharmaceutical companies working on this emerging field, we should most certainly see interesting progress and efficient novel anti-influenza therapies reaching regulatory market approval in a near future.

In the context of a globalized world facing major vicissitudes including population dynamics, climate change and the multiple emergence/re-emergence of zoonotic viruses, the effectiveness and reaction force of the classic de novo development of antivirals is challenged. Despite inherent limits, drug repurposing offers a very large palette of possibilities to rapidly and efficiently find new antiviral drugs.

\section{AUTHOR CONTRIBUTIONS}

All authors listed have made a substantial, direct and intellectual contribution to the work, and approved it for publication.

\section{ACKNOWLEDGMENTS}

This work was funded by grants from the French Ministry of Social Affairs and Health (DGOS), Institut National de la Santé et de la Recherche Médicale (INSERM), the Université Claude Bernard Lyon 1, the Région Auvergne Rhône-Alpes (CMIRA N ${ }^{\circ}$ 14007029, and AccueilPro COOPERA N ${ }^{\circ} 15458$ grants).

9. Paules CI, Marston HD, Eisinger RW, Baltimore D, Fauci AS. The pathway to a universal influenza vaccine. Immunity. (2017) 47:599-603. doi: 10.1016/j.immuni.2017.09.007

10. Khurana S. Development and regulation of novel influenza virus vaccines: a United States young scientist perspective. Vaccines. (2018) 6:E24. doi: $10.3390 /$ vaccines6020024

11. Nguyen-Van-Tam JS, Venkatesan S, Muthuri SG, Myles PR. Neuraminidase inhibitors: who, when, where? Clin Microbiol Infect. (2015) 21:222-5. doi: 10.1016/j.cmi.2014.11.020

12. Sugaya N. Widespread use of neuraminidase inhibitors in Japan. J Infect Chemother. (2011) 17:595-601. doi: 10.1007/s10156-011-0288-0

13. WHO. WHO Guidelines for Pharmacological Management of Pandemic (H1N1) Influenza and Other Influenza Viruses. WHO (2009). Available online at: http://www.who.int/csr/resources/publications/swineflu/h1n1_ use_antivirals_20090820/en/ (Accessed January 24, 2019).

14. Moscona A. Neuraminidase inhibitors for influenza. N Engl J Med. (2005) 353:1363-73. doi: 10.1056/NEJMra050740

15. McKimm-Breschkin JL. Influenza neuraminidase inhibitors: antiviral action and mechanisms of resistance. Influenza Other Respir Viruses. (2013) 7:2536. doi: 10.1111/irv.12047

16. Sunagawa S, Higa F, Cash HL, Tateyama M, Uno T, Fujita J. Singledose inhaled laninamivir: registered in Japan and its potential role in control of influenza epidemics. Influenza Other Respir Viruses. (2013) 7:1-3. doi: 10.1111/j.1750-2659.2012.00351.x

17. Jefferson T, Jones MA, Doshi P, Del Mar CB, Hama R, Thompson MJ, et al. Neuraminidase inhibitors for preventing and treating influenza in healthy adults and children. Cochrane Database Syst Rev. (2014) CD008965. doi: 10.1002/14651858.CD008965.pub4 
18. Dobson J, Whitley RJ, Pocock S, Monto AS. Oseltamivir treatment for influenza in adults: a meta-analysis of randomised controlled trials. Lancet. (2015) 385:1729-37. doi: 10.1016/S0140-6736(14)62449-1

19. Venkatesan S, Myles PR, Leonardi-Bee J, Muthuri SG, Al Masri M, Andrews $\mathrm{N}$, et al. Impact of outpatient neuraminidase inhibitor treatment in patients infected with influenza $\mathrm{A}(\mathrm{H} 1 \mathrm{~N} 1)$ pdm09 at high risk of hospitalization: an individual participant data metaanalysis. Clin Infect Dis. (2017) 64:1328-34. doi: $10.1093 / \mathrm{cid} / \mathrm{cix} 127$

20. Li TCM, Chan MCW, Lee N. Clinical implications of antiviral resistance in influenza. Viruses. (2015) 7:4929-44. doi: 10.3390/v7092850

21. Kamali A, Holodniy M. Influenza treatment and prophylaxis with neuraminidase inhibitors: a review. Infect Drug Resist. (2013) 6:187-98. doi: 10.2147/IDR.S36601

22. Takashita E, Meijer A, Lackenby A, Gubareva L, Rebelo-de-Andrade H, Besselaar T, et al. Global update on the susceptibility of human influenza viruses to neuraminidase inhibitors, 2013-2014. Antiviral Res. (2015) 117:2738. doi: 10.1016/j.antiviral.2015.02.003

23. Hurt AC, Hardie K, Wilson NJ, Deng Y-M, Osbourn M, Gehrig N, et al. Community transmission of oseltamivir-resistant A(H1N1)pdm09 influenza. N Engl J Med. (2011) 365:2541-2. doi: 10.1056/NEJMc1111078

24. Cheung PPH, Watson SJ, Choy K-T, Fun Sia S, Wong DDY, Poon LLM, et al. Generation and characterization of influenza A viruses with altered polymerase fidelity. Nat Commun. (2014) 5:4794. doi: 10.1038/ncomms5794

25. Sissoko D, Laouenan C, Folkesson E, M'Lebing A-B, Beavogui A-H, Baize S, et al. Experimental treatment with favipiravir for ebola virus disease (the JIKI Trial): a historically controlled, single-arm proof-of-concept trial in Guinea. PLoS Med. (2016) 13:e1001967. doi: 10.1371/journal.pmed.1001967

26. McKimm-Breschkin JL, Jiang S, Hui DS, Beigel JH, Govorkova EA, Lee N. Prevention and treatment of respiratory viral infections: presentations on antivirals, traditional therapies and host-directed interventions at the 5th ISIRV Antiviral Group conference. Antiviral Res. (2018) 149:118-42. doi: 10.1016/j.antiviral.2017.11.013

27. Noshi T, Kitano M, Taniguchi K, Yamamoto A, Omoto S, Baba K, et al. In vitro characterization of baloxavir acid, a first-in-class capdependent endonuclease inhibitor of the influenza virus polymerase PA subunit. Antiviral Res. (2018) 160:109-17. doi: 10.1016/j.antiviral.2018. 10.008

28. Hayden FG, Sugaya N, Hirotsu N, Lee N, de Jong MD, Hurt AC, et al. Baloxavir marboxil for uncomplicated influenza in adults and adolescents. N Engl J Med. (2018) 379:913-23. doi: 10.1056/NEJMoa1716197

29. Roche Announces FDA Approval of Xofluza (baloxavir marboxil) for Influenza. Available online at: https://www.roche.com/de/media/releases/ med-cor-2018-10-24.htm (Accessed October 28, 2018).

30. Omoto S, Speranzini V, Hashimoto T, Noshi T, Yamaguchi H, Kawai M, et al. Characterization of influenza virus variants induced by treatment with the endonuclease inhibitor baloxavir marboxil. Sci Rep. (2018) 8:9633. doi: 10.1038/s41598-018-27890-4

31. Jackson GG, Muldoon RL, Akers LW. Serological evidence for prevention of influenzal infection in volunteers by an anti-influenzal drug adamantanamine hydrochloride. Antimicrob Agents Chemother. (1963) 161:703-7.

32. Rabinovich S, Baldini JT, Bannister R. Treatment of influenza. The therapeutic efficacy of rimantadine $\mathrm{HC} 1$ in a naturally occurring influenza A2 outbreak. Am J Med Sci. (1969) 257:328-35.

33. Kim CU, Lew W, Williams MA, Wu H, Zhang L, Chen X, et al. Structureactivity relationship studies of novel carbocyclic influenza neuraminidase inhibitors. J Med Chem. (1998) 41:2451-60. doi: 10.1021/jm980162u

34. von Itzstein M, Wu WY, Kok GB, Pegg MS, Dyason JC, Jin B, et al. Rational design of potent sialidase-based inhibitors of influenza virus replication. Nature. (1993) 363:418-23. doi: 10.1038/363418a0

35. Babu YS, Chand P, Bantia S, Kotian P, Dehghani A, El-Kattan Y, et al. BCX1812 (RWJ-270201): discovery of a novel, highly potent, orally active, and selective influenza neuraminidase inhibitor through structure-based drug design. J Med Chem. (2000) 43:3482-3486. doi: 10.1021/jm0002679

36. Yamashita M, Tomozawa T, Kakuta M, Tokumitsu A, Nasu H, Kubo S. CS8958, a prodrug of the new neuraminidase inhibitor R-125489, shows longacting anti-influenza virus activity. Antimicrob Agents Chemother. (2009) 53:186-92. doi: 10.1128/AAC.00333-08
37. Furuta Y, Takahashi K, Fukuda Y, Kuno M, Kamiyama T, Kozaki $\mathrm{K}$, et al. In vitro and in vivo activities of anti-influenza virus compound T-705. Antimicrob Agents Chemother. (2002) 46:977-81. doi: $10.1177 / 095632020301400502$

38. Strittmatter SM. Overcoming drug development bottlenecks with repurposing: old drugs learn new tricks. Nat Med. (2014) 20:590-1. doi: $10.1038 / \mathrm{nm} .3595$

39. Drug Innovation. Novel Drug Approvals for 2018. (2018) Available online at: https://www.fda.gov/Drugs/DevelopmentApprovalProcess/ DrugInnovation/ucm592464.htm (Accessed October 28, 2018).

40. Chart Pack: Biopharmaceuticals in Perspective, Summer 2018. Phrma (2018). Available online at: http://www.phrma.org/report/chart-packbiopharmaceuticals-in-perspective-summer-2018 (Accessed October 28, 2018).

41. Ashburn TT, Thor KB. Drug repositioning: identifying and developing new uses for existing drugs. Nat Rev Drug Discov. (2004) 3:673-83. doi: $10.1038 / \mathrm{nrd} 1468$

42. Pushpakom S, Iorio F, Eyers PA, Escott KJ, Hopper S, Wells A, et al. Drug repurposing: progress, challenges and recommendations. Nat Rev Drug Discov. (2018). doi: 10.1038/nrd.2018.168. [Epub ahead of print].

43. Devillers J. Repurposing drugs for use against Zika virus infection. SAR QSAR Environ Res. (2018) 29:103-15. doi: 10.1080/1062936X.2017.1411642

44. Hernandez JJ, Pryszlak M, Smith L, Yanchus C, Kurji N, Shahani VM, et al. Giving drugs a second chance: overcoming regulatory and financial hurdles in repurposing approved drugs as cancer therapeutics. Front Oncol. (2017) 7:273. doi: $10.3389 /$ fonc. 2017.00273

45. Rehman W, Arfons LM, Lazarus HM. The rise, fall and subsequent triumph of thalidomide: lessons learned in drug development. Ther Adv Hematol. (2011) 2:291-308. doi: 10.1177/2040620711413165

46. Ghofrani HA, Osterloh IH, Grimminger F. Sildenafil: from angina to erectile dysfunction to pulmonary hypertension and beyond. Nat Rev Drug Discov. (2006) 5:689-702. doi: 10.1038/nrd2030

47. Coleman CM, Sisk JM, Mingo RM, Nelson EA, White JM, Frieman MB. Abelson kinase inhibitors are potent inhibitors of severe acute respiratory syndrome coronavirus and middle east respiratory syndrome coronavirus fusion. J Virol. (2016) 90:8924-33. doi: 10.1128/JVI.01429-16

48. Hopkins AL. Network pharmacology: the next paradigm in drug discovery. Nat Chem Biol. (2008) 4:682-90. doi: 10.1038/nchembio.118

49. Hopkins AL. Drug discovery: predicting promiscuity. Nature. (2009) 462:167-8. doi: 10.1038/462167a

50. Reddy AS, Zhang S. Polypharmacology: drug discovery for the future. Expert Rev Clin Pharmacol. (2013) 6:41-7. doi: 10.1586/ecp.12.74

51. Medina-Franco JL, Giulianotti MA, Welmaker GS, Houghten RA. Shifting from the single- to the multitarget paradigm in drug discovery. Drug Discov Today. (2013) 18:495-501. doi: 10.1016/j.drudis.2013.01.008

52. Naveja JJ, Dueñas-González A, Medina-Franco JL. Chapter 12 - drug repurposing for epigenetic targets guided by computational methods. In: Epi-Informatics, ed J. L. Medina-Franco (Boston: Academic Press), 327-57. doi: 10.1016/B978-0-12-802808-7.00012-5

53. Moffat JG, Vincent F, Lee JA, Eder J, Prunotto M. Opportunities and challenges in phenotypic drug discovery: an industry perspective. Nat Rev Drug Discov. (2017) 16:531-43. doi: 10.1038/nrd.2017.111

54. Swinney DC, Anthony J. How were new medicines discovered? Nat Rev Drug Discov. (2011) 10:507-19. doi: 10.1038/nrd3480

55. Bastos LFS, Coelho MM. Drug repositioning: playing dirty to kill pain. CNS Drugs. (2014) 28:45-61. doi: 10.1007/s40263-013-0128-0

56. Loregian A, Palù G. How academic labs can approach the drug discovery process as a way to synergize with big pharma. Trends Microbiol. (2013) 21:261-4. doi: 10.1016/j.tim.2013.03.006

57. Jones LH, Bunnage ME. Applications of chemogenomic library screening in drug discovery. Nat Rev Drug Discov. (2017) 16:285-96. doi: $10.1038 /$ nrd.2016.244

58. Knox C, Law V, Jewison T, Liu P, Ly S, Frolkis A, Pon A, et al. DrugBank 3.0: a comprehensive resource for "omics" research on drugs. Nucleic Acids Res. (2011) 39:D1035-41. doi: 10.1093/nar/gkq1126

59. Ferrero E, Dunham I, Sanseau P. In silico prediction of novel therapeutic targets using gene-disease association data. J Transl Med. (2017) 15:182. doi: 10.1186/s12967-017-1285-6 
60. Hurle MR, Yang L, Xie Q, Rajpal DK, Sanseau P, Agarwal P. Computational drug repositioning: from data to therapeutics. Clin Pharmacol Ther. (2013) 93:335-41. doi: 10.1038/clpt.2013.1

61. Ekins S, Mestres J, Testa B. In silico pharmacology for drug discovery: methods for virtual ligand screening and profiling. Br J Pharmacol. (2007) 152:9-20. doi: 10.1038/sj.bjp.0707305

62. Tari LB, Patel JH. Systematic drug repurposing through text mining. Methods Mol Biol. (2014) 1159:253-67. doi: 10.1007/978-1-4939-0709-0_14

63. Cichonska A, Rousu J, Aittokallio T. Identification of drug candidates and repurposing opportunities through compound-target interaction networks. Expert Opin Drug Discov. (2015) 10:1333-45. doi: 10.1517/17460441.2015.1096926

64. Sidders B, Karlsson A, Kitching L, Torella R, Karila P, Phelan A. Networkbased drug discovery: coupling network pharmacology with phenotypic screening for neuronal excitability. J Mol Biol. (2018) 430:3005-15. doi: 10.1016/j.jmb.2018.07.016

65. Chatterjee S, Szustakowski JD, Nanguneri NR, Mickanin C, Labow MA, Nohturfft A, et al. Identification of novel genes and pathways regulating SREBP transcriptional activity. PLoS ONE. (2009) 4:5197. doi: 10.1371/journal.pone.0005197

66. Oprea TI, Nielsen SK, Ursu O, Yang JJ, Taboureau O, Mathias SL, et al. Associating drugs, targets and clinical outcomes into an integrated network affords a new platform for computer-aided drug repurposing. Mol Inform. (2011) 30:100-11. doi: 10.1002/minf.201100023

67. Chiang AP, Butte AJ. Systematic evaluation of drug-disease relationships to identify leads for novel drug uses. Clin Pharmacol Ther. (2009) 86:507-510. doi: 10.1038/clpt.2009.103

68. Platz EA, Yegnasubramanian S, Liu JO, Chong CR, Shim JS, Kenfield SA, et al. A novel two-stage, transdisciplinary study identifies digoxin as a possible drug for prostate cancer treatment. Cancer Discov. (2011) 1:68-77. doi: 10.1158/2159-8274.CD-10-0020

69. Allarakhia M. Open-source approaches for the repurposing of existing or failed candidate drugs: learning from and applying the lessons across diseases. Drug Des Devel Ther. (2013) 7:753-66. doi: 10.2147/DDDT. S46289

70. van der Graaf PH, Benson N. Systems pharmacology: bridging systems biology and pharmacokinetics-pharmacodynamics (PKPD) in drug discovery and development. Pharm Res. (2011) 28:1460-4. doi: 10.1007/s11095-011-0467-9

71. Zhou W, Wang Y, Lu A, Zhang G. Systems pharmacology in small molecular drug discovery. Int J Mol Sci. (2016) 17:246. doi: 10.3390/ijms17020246

72. Mercorelli B, Palù G, Loregian A. Drug repurposing for viral infectious diseases: how far are we? Trends Microbiol. (2018) 26:865-76. doi: 10.1016/j.tim.2018.04.004

73. Akpovwa H. Chloroquine could be used for the treatment of filoviral infections and other viral infections that emerge or emerged from viruses requiring an acidic pH for infectivity. Cell Biochem Funct. (2016) 34:191-6. doi: $10.1002 / \mathrm{cbf} .3182$

74. Al-Bari MAA. Targeting endosomal acidification by chloroquine analogs as a promising strategy for the treatment of emerging viral diseases. Pharmacol Res Perspect. (2017) 5:e00293. doi: 10.1002/prp2.293

75. Pires de Mello CP, Tao X, Kim TH, Vicchiarelli M, Bulitta JB, Kaushik A, et al. Clinical regimens of favipiravir inhibit zika virus replication in the hollowfiber infection model. Antimicrob Agents Chemother. (2018) 62:e00967-18. doi: 10.1128/AAC.00967-18

76. Ludwig S. Will omics help to cure the flu? Trends Microbiol. (2014) 22:232-3. doi: 10.1016/j.tim.2014.03.003

77. Perwitasari O, Yan X, O’Donnell J, Johnson S, Tripp RA. Repurposing kinase inhibitors as antiviral agents to control influenza a virus replication. Assay Drug Dev Technol. (2015) 13:638-49. doi: 10.1089/adt.2015.0003.drrr

78. Fedson DS. Treating influenza with statins and other immunomodulatory agents. Antiviral Res. (2013) 99:417-35. doi: 10.1016/j.antiviral.2013.06.018

79. Fedson DS. Clinician-initiated research on treating the host response to pandemic influenza. Hum Vaccin Immunother. (2018) 14:790-5. doi: 10.1080/21645515.2017.1378292

80. Mehrbod P, Omar AR, Hair-Bejo M, Haghani A, Ideris A. Mechanisms of action and efficacy of statins against influenza. Biomed Res Int. (2014) 2014:872370. doi: $10.1155 / 2014 / 872370$
81. Rossignol JF, La Frazia S, Chiappa L, Ciucci A, Santoro MG. Thiazolides, a new class of anti-influenza molecules targeting viral hemagglutinin at the post-translational level. J Biol Chem. (2009) 284:29798-808. doi: 10.1074/jbc.M109.029470

82. Tilmanis D, van Baalen C, Oh DY, Rossignol J-F, Hurt AC. The susceptibility of circulating human influenza viruses to tizoxanide, the active metabolite of nitazoxanide. Antiviral Res. (2017) 147:142-8. doi: 10.1016/j.antiviral.2017.10.002

83. Moseley CE, Webster RG, Aldridge JR. Peroxisome proliferator-activated receptor and AMP-activated protein kinase agonists protect against lethal influenza virus challenge in mice. Influenza Other Respir Viruses. (2010) 4:307-11. doi: 10.1111/j.1750-2659.2010.00155.x

84. Budd A, Alleva L, Alsharifi M, Koskinen A, Smythe V, Müllbacher $A$, et al. Increased survival after gemfibrozil treatment of severe mouse influenza. Antimicrob Agents Chemother. (2007) 51:2965-8. doi: 10.1128/AAC.00219-07

85. Droebner K, Haasbach E, Dudek SE, Scheuch G, Nocker K, Canisius S, et al. Pharmacodynamics, pharmacokinetics, and antiviral activity of BAY 818781, a novel NF-кB inhibiting anti-influenza drug. Front Microbiol. (2017) 8:2130. doi: 10.3389/fmicb.2017.02130

86. Scheuch G, Canisius S, Nocker K, Hofmann T, Naumann R, Pleschka S, et al. Targeting intracellular signaling as an antiviral strategy: aerosolized LASAG for the treatment of influenza in hospitalized patients. Emerg Microbes Infect. (2018) 7:21. doi: 10.1038/s41426-018-0023-3

87. Davidson S. Treating influenza infection, from now and into the future. Front Immunol. (2018) 9:1946. doi: 10.3389/fimmu.2018.01946

88. Carey MA, Bradbury JA, Rebolloso YD, Graves JP, Zeldin DC, Germolec DR. Pharmacologic inhibition of COX-1 and COX-2 in influenza A viral infection in mice. PLoS ONE. (2010) 5:e11610. doi: 10.1371/journal.pone.0011610

89. Shi X, Zhou W, Huang H, Zhu H, Zhou P, Zhu H, et al. Inhibition of the inflammatory cytokine tumor necrosis factor-alpha with etanercept provides protection against lethal $\mathrm{H} 1 \mathrm{~N} 1$ influenza infection in mice. Crit Care. (2013) 17:R301 doi: 10.1186/cc13171

90. Denisova OV, Kakkola L, Feng L, Stenman J, Nagaraj A, Lampe J, et al. Obatoclax, saliphenylhalamide, and gemcitabine inhibit influenza a virus infection. J Biol Chem. (2012) 287:35324-32. doi: 10.1074/jbc.M112.392142

91. Hu Y, Zhang J, Musharrafieh RG, Ma C, Hau R, Wang J. Discovery of dapivirine, a nonnucleoside HIV-1 reverse transcriptase inhibitor, as a broadspectrum antiviral against both influenza A and B viruses. Antiviral Res. (2017) 145:103-13. doi: 10.1016/j.antiviral.2017.07.016

92. Schräder T, Dudek SE, Schreiber A, Ehrhardt C, Planz O, Ludwig S. The clinically approved MEK inhibitor Trametinib efficiently blocks influenza A virus propagation and cytokine expression. Antiviral Res. (2018) 157:80-92. doi: 10.1016/j.antiviral.2018.07.006

93. Rohini K, Shanthi V. Hyphenated 3D-QSAR statistical model-drug repurposing analysis for the identification of potent neuraminidase inhibitor. Cell Biochem Biophys. (2018) 76:357-76. doi: 10.1007/s12013-018-0844-7

94. Lejal N, Tarus B, Bouguyon E, Chenavas S, Bertho N, Delmas B, et al. Structure-based discovery of the novel antiviral properties of naproxen against the nucleoprotein of influenza A virus. Antimicrob Agents Chemother. (2013) 57:2231-42. doi: 10.1128/AAC.02335-12

95. Bao J, Marathe B, Govorkova EA, Zheng JJ. Drug repurposing identifies inhibitors of oseltamivir-resistant influenza viruses. Angew Chem Int Ed Engl. (2016) 55:3438-41. doi: 10.1002/anie.201511361

96. Watanabe T, Kawakami E, Shoemaker JE, Lopes TJS, Matsuoka Y, Tomita $\mathrm{Y}$, et al. Influenza virus-host interactome screen as a platform for antiviral drug development. Cell Host Microbe. (2014) 16:795-805 doi: 10.1016/j.chom.2014.11.002

97. Josset L, Textoris J, Loriod B, Ferraris O, Moules V, Lina B, et al. Gene expression signature-based screening identifies new broadly effective influenza a antivirals. PLoS ONE. (2010) 5:13169. doi: 10.1371/journal.pone.0013169

98. Pizzorno A, Terrier O, Nicolas de Lamballerie C, Julien T, Padey B, Traversier A, et al. Repurposing of drugs as novel influenza inhibitors from clinical gene expression infection signatures. Front Immunol. (2019) 10:60. doi: 10.3389/fimmu.2019.00060

99. Kumaki Y, Morrey JD, Barnard DL. Effect of statin treatments on highly pathogenic avian influenza H5N1, seasonal and H1N1pdm09 
virus infections in BALB/c mice. Future Virol. (2012) 7:801-18. doi: $10.2217 / f v l .12 .71$

100. Salomon R, Hoffmann E, Webster RG. Inhibition of the cytokine response does not protect against lethal H5N1 influenza infection. Proc Natl Acad Sci USA. (2007) 104:12479-81. doi: 10.1073/pnas.0705289104

101. Belser JA, Szretter KJ, Katz JM, Tumpey TM. Simvastatin and oseltamivir combination therapy does not improve the effectiveness of oseltamivir alone following highly pathogenic avian $\mathrm{H} 5 \mathrm{~N} 1$ influenza virus infection in mice. Virology. (2013) 439:42-6. doi: 10.1016/j.virol.2013.01.017

102. Radigan KA, Urich D, Misharin AV, Chiarella SE, Soberanes S, Gonzalez A, et al. The effect of rosuvastatin in a murine model of influenza A infection. PLoS ONE. (2012) 7:e35788. doi: 10.1371/journal.pone.0035788

103. Enserink M. Infectious disease. Old drugs losing effectiveness against flu; could statins fill gap? Science. (2005) 309:1976-7. doi: 10.1126/science.309.5743.1976a

104. Vandermeer ML, Thomas AR, Kamimoto L, Reingold A, Gershman K, Meek J, et al. Association between use of statins and mortality among patients hospitalized with laboratory-confirmed influenza virus infections: a multistate study. J Infect Dis. (2012) 205:13-9. doi: 10.1093/infdis/jir695

105. Brett SJ, Myles P, Lim WS, Enstone JE, Bannister B, Semple MG, et al. Pre-admission statin use and in-hospital severity of 2009 pandemic influenza $\mathrm{A}(\mathrm{H} 1 \mathrm{~N} 1)$ disease. PLoS ONE. (2011) 6:e18120. doi: 10.1371/journal.pone.0018120

106. Rossignol J-F. Nitazoxanide: a first-in-class broad-spectrum antiviral agent. Antiviral Res. (2014) 110:94-103. doi: 10.1016/j.antiviral.2014.07.014

107. Haffizulla J, Hartman A, Hoppers M, Resnick H, Samudrala S, Ginocchio C, et al. Effect of nitazoxanide in adults and adolescents with acute uncomplicated influenza: a double-blind, randomised, placebo-controlled, phase $2 \mathrm{~b} / 3$ trial. Lancet Infect Dis. (2014) 14:609-18. doi: 10.1016/S1473-3099(14)70717-0

108. Mazur I, Wurzer WJ, Ehrhardt C, Pleschka S, Puthavathana P, Silberzahn T, et al. Acetylsalicylic acid (ASA) blocks influenza virus propagation via its NF-kappaB-inhibiting activity. Cell Microbiol. (2007) 9:1683-94. doi: $10.1111 / j .1462-5822.2007 .00902 . x$

109. Yin MJ, Yamamoto Y, Gaynor RB. The anti-inflammatory agents aspirin and salicylate inhibit the activity of I(kappa)B kinase-beta. Nature. (1998) 396:77-80. doi: 10.1038/23948

110. Wurzer WJ, Ehrhardt C, Pleschka S, Berberich-Siebelt F, Wolff T, Walczak $\mathrm{H}$, et al. NF-kappaB-dependent induction of tumor necrosis factorrelated apoptosis-inducing ligand (TRAIL) and Fas/FasL is crucial for efficient influenza virus propagation. J Biol Chem. (2004) 279:30931-7. doi: 10.1074/jbc.M403258200

111. Tarus B, Chevalier C, Richard C-A, Delmas B, Di Primo C, Slama-Schwok A. Molecular dynamics studies of the nucleoprotein of influenza A virus: role of the protein flexibility in RNA binding. PLoS ONE. (2012) 7:e30038. doi: 10.1371/journal.pone. 0030038

112. Dilly S, Fotso Fotso A, Lejal N, Zedda G, Chebbo M, Rahman F, et al. From naproxen repurposing to naproxen analogues and their antiviral activity against influenza A virus. J Med Chem. (2018) 61:7202-17. doi: 10.1021/acs.jmedchem.8b00557

113. Chaudhuri S, Symons JA, Deval J. Innovation and trends in the development and approval of antiviral medicines: 1987-2017 and beyond. Antiviral Res. (2018) 155:76-88. doi: 10.1016/j.antiviral.2018.05.005

114. Pizzorno A, Abed Y, Rhéaume C, Boivin G. Oseltamivir-zanamivir combination therapy is not superior to zanamivir monotherapy in mice infected with influenza $\mathrm{A}(\mathrm{H} 3 \mathrm{~N} 2)$ and $\mathrm{A}(\mathrm{H} 1 \mathrm{~N} 1) \mathrm{pdm} 09$ viruses. Antiviral Res. (2014) 105:54-8. doi: 10.1016/j.antiviral.2014.02.017

115. Escuret V, Cornu C, Boutitie F, Enouf V, Mosnier A, BouscambertDuchamp $\mathrm{M}$, et al. Oseltamivir-zanamivir bitherapy compared to oseltamivir monotherapy in the treatment of pandemic 2009 influenza A(H1N1) virus infections. Antiviral Res. (2012) 96:130-7. doi: 10.1016/j.antiviral.2012.08.002

116. Carrat F, Duval X, Tubach F, Mosnier A, Van der Werf S, Tibi A, et al. Effect of oseltamivir, zanamivir or oseltamivir-zanamivir combination treatments on transmission of influenza in households. Antivir Ther. (2012) 17:1085-90. doi: 10.3851/IMP2128

117. Belardo G, Cenciarelli O, La Frazia S, Rossignol JF, Santoro MG. Synergistic effect of nitazoxanide with neuraminidase inhibitors against influenza A viruses in vitro. Antimicrob Agents Chemother. (2015) 59:1061-9. doi: 10.1128/AAC.03947-14

118. Hung IFN, To KKW, Chan JFW, Cheng VCC, Liu KSH, Tam A, et al. Efficacy of clarithromycin-naproxen-oseltamivir combination in the treatment of patients hospitalized for influenza $\mathrm{A}(\mathrm{H} 3 \mathrm{~N} 2)$ infection: an openlabel randomized, controlled, phase IIb/III trial. Chest. (2017) 151:1069-80. doi: 10.1016/j.chest.2016.11.012

Conflict of Interest Statement: AP, BP, OT, and MR-C are co-inventors of two patent applications filed by INSERM, Université Claude Bernard Lyon 1, Laval University and Hospices Civils de Lyon for the repurposing of drugs as anti-influenza agents (WO/2016/146836 and WO/2017/174593).

Copyright (๑) 2019 Pizzorno, Padey, Terrier and Rosa-Calatrava. This is an openaccess article distributed under the terms of the Creative Commons Attribution License (CC BY). The use, distribution or reproduction in other forums is permitted, provided the original author(s) and the copyright owner(s) are credited and that the original publication in this journal is cited, in accordance with accepted academic practice. No use, distribution or reproduction is permitted which does not comply with these terms. 